\title{
Metazoan tsRNAs: Biogenesis, Evolution and Regulatory Functions
}

\author{
Shengqian Dou ${ }^{+}\left(\mathbb{D}\right.$, Yirong Wang ${ }^{\dagger}$ and Jian $\mathrm{Lu}^{*}{ }^{\mathbb{C}}$ \\ State Key Laboratory of Protein and Plant Gene Research, Center for Bioinformatics, School of Life Sciences, \\ Peking University, Beijing 100871, China; sqdou@pku.edu.cn (S.D.); yr.wang@pku.edu.cn (Y.W.) \\ * Correspondence: LUJ@pku.edu.cn; Tel.: +86-10-62750246 \\ + These authors contributed equally to the paper.
}

Received: 16 January 2019; Accepted: 12 February 2019; Published: 18 February 2019

\begin{abstract}
Transfer RNA-derived small RNAs (tsRNAs) are an emerging class of regulatory non-coding RNAs that play important roles in post-transcriptional regulation across a variety of biological processes. Here, we review the recent advances in tsRNA biogenesis and regulatory functions from the perspectives of functional and evolutionary genomics, with a focus on the tsRNA biology of Drosophila. We first summarize our current understanding of the biogenesis mechanisms of different categories of tsRNAs that are generated under physiological or stressed conditions. Next, we review the conservation patterns of tsRNAs in all domains of life, with an emphasis on the conservation of tsRNAs between two Drosophila species. Then, we elaborate the currently known regulatory functions of tsRNAs in mRNA translation that are independent of, or dependent on, Argonaute (AGO) proteins. We also highlight some issues related to the fundamental biology of tsRNAs that deserve further study.
\end{abstract}

Keywords: tRNA-derived small RNAs; tsRNAs; translational regulation; stress response; Argonaute

\section{Introduction}

Transfer RNAs (tRNAs) are a class of non-coding RNAs that are crucial for protein synthesis in both prokaryotic and eukaryotic cells. Metazoan small non-coding RNAs, such as microRNAs (miRNAs), small interfering RNAs (siRNAs) and PIWI-interacting RNAs (piRNAs), regulate gene expression via the RNA interference (RNAi) mechanism [1,2]. With the advent of deep-sequencing, a large number of tRNA-derived small RNAs (tsRNAs, also called "tRNA-derived fragments" or tRFs) have been discovered in various species ranging from prokaryotes to eukaryotes [3-9], which has considerably expanded the small RNA repertoire. Many studies suggest that tsRNAs are not random degradation products of tRNAs but play important roles in many cellular activities such as DNA damage response [10], cell proliferation and cancer progression [11-14], transposon silencing [15,16], sperm maturation [6,17], and epigenetic inheritance of metabolism-alteration induced traits [18]. Collectively, these studies have significantly advanced our understanding of the biogenesis and the molecular functions of tsRNAs [5,19-22].

Here, we review the recent advances in tsRNA biogenesis and regulatory functions from the perspectives of functional and evolutionary genomics, with a focus on the tsRNA biology of Drosophila as revealed by our recent study [23].

\section{The Biogenesis of tsRNAs under Physiological and Stressed Conditions}

The cloverleaf structure of a tRNA typically contains a D-loop, an anticodon loop, a variable loop, a T-loop, and an amino acid acceptor stem [24] (Figure 1A). Different endonucleases can cleave tRNAs at specific sites, generating tsRNAs of different categories [5,7,19-22,25]. tsRNAs can also be 
derived from pre-tRNAs [26]; here we will focus on those derived from mature tRNAs. Based on the cleavage sites in tRNAs, tsRNAs derived from mature tRNAs can be broadly divided into two categories (Figure 1A).

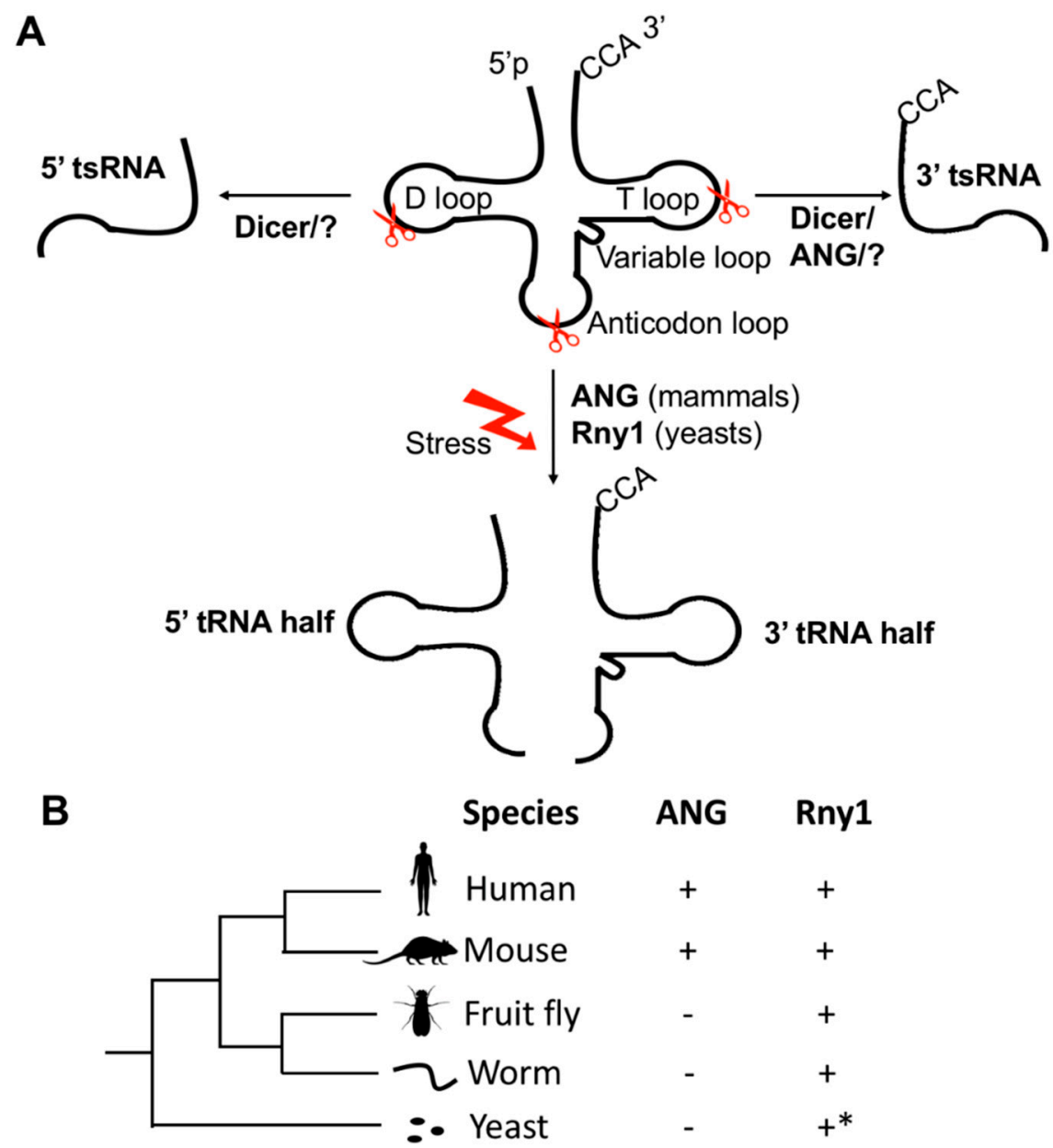

Figure 1. The biogenesis of tRNA-derived small RNAs (tsRNAs) from mature transfer RNAs (tRNAs). (A) Processing and classification of tsRNAs derived from mature tRNAs. The cleavage of an RNase at the D-loop or T-loop of a tRNA can generate a $5^{\prime}$ or $3^{\prime}$ tsRNA, respectively. The $5^{\prime}$ tsRNA could be generated by DCR, while $3^{\prime}$ tsRNA could be produced by DCR or ANG. Other unknown RNases (?) might also participate in tsRNA generation. The tRNA halves are cleaved by Rny1 and angiogenin (ANG) in yeasts and mammals, respectively. (B) The conservation patterns of Rny1 and ANG in eukaryotes. Among the five representative species, ANG is only present in humans and mice. Although the homologous sequence of Rny1 can be found in all the five species, currently Rny1 is only demonstrated to be involved in the biogenesis of tRNA halves in yeasts.

The first category is produced by specific cleavage in the anticodon loop of a mature tRNA to generate a "tRNA half" which is $\sim 35 \mathrm{nt}$ in length $[27,28]$. The production of tRNA halves is inducible upon various cellular stresses, such as oxidative stress [29,30], arsenite, heat shock, ultraviolet irradiation [31], or virus infection [32]; therefore, tRNA halves are also called tRNA-derived stress-induced RNAs (tiRNAs) [31,33,34]. In yeasts and mammals, the tRNA-halves are cleaved by Rny1 [35] and angiogenin (ANG) [31], respectively. Rny1 is a member of the RNase T2 family that is conserved in eukaryotic genomes [36]. Interestingly, although the deletion of Rny1 in yeast can be rescued by human RNASET2 (the ortholog of Rny1), no evidence has been found that human RNASET2 participates in the biogenesis of tsRNAs in the stressed human cells [35] (Figure 1B). ANG, a vertebrate-specific member of the RNase A family, is only present in certain vertebrates, and its ortholog cannot be found in yeasts or 
invertebrates such as Drosophila and worms [37] (Figure 1B). Therefore, the biogenesis mechanisms of tRNA-halves have evolved in eukaryotes.

The secondary category of tsRNAs are cleaved in the D-loop or T-loop of a tRNA to produce short $5^{\prime}$-tsRNAs or $3^{\prime}$-tsRNAs, which are $15-32 \mathrm{nt}$ in length $[27,28]$. It is reported that ANG is involved in the production of $3^{\prime}$-tsRNAs [38]. Some studies suggest the biogenesis of this category of tsRNAs might be dependent on Dicer [9,10,39], however, others suggest Dicer is not essential for biogenesis of the tsRNAs $[27,28,38,40]$. These discrepant observations might be caused by the fact that tsRNAs of this category are generated by diverse mechanisms that are not evolutionarily conserved, although we cannot exclude the possibility that these discrepant observations might be caused by variations in experimental approaches and platforms used by different studies. Overall, the mechanism by which this category of tsRNAs is cleaved is yet not well understood.

Here, we collectively called the two categories of tRNA-derived small RNAs tsRNAs, unless specifically noted. The majority of tsRNAs are located in the $5^{\prime}$-end of tRNAs in mammals $[22,27,28]$ and Drosophila [23,27]. Also, tsRNAs are preferentially generated from particular tRNAs [27]. For example, in Drosophila, the tsRNAs are significantly enriched in tRNA ${ }^{\text {Gly }}$, tRNA ${ }^{\text {Glu }}$, tRNA ${ }^{\text {Lys, }}$, and tRNA ${ }^{\text {Asp }}$ [23]. Of note, the observation that the majority of tsRNAs are derived from the $5^{\prime}$-end of tRNAs and from specific tRNAs might also be caused by sequencing bias of specific tRNA species. For instance, the post-transcriptional modifications on certain tRNAs can interfere with reverse transcription and sequencing, especially for tsRNAs or mature tRNAs [41,42]. Interestingly, the temporal and spatial expression patterns of tsRNAs are regulated during animal development $[5,27,28,43,44]$. By examining 495 Drosophila small RNA libraries that span 21 cell lines or developmental stages, we found the abundance ratio of tsRNAs to miRNAs varied widely across samples, with the ratio highest in pupae and lowest in embryos and adult heads [23]. Moreover, the expression levels of tsRNAs and their binding of the Argonaute (AGO) proteins are age-dependent in Drosophila [43]. In addition, some short tsRNAs could also be induced by stress; for example, a class of 19-nt tsRNAs is produced in phosphate-starved roots of Arabidopsis [45].

\section{Conservation of tsRNAs in the Tree of Life}

The RNAi-based small RNA pathways are not evolutionarily conserved in eukaryotes. The siRNA pathway is the most ancient form; the miRNA pathways originated independently in plants and animals, and the piRNA pathway is primarily present in animal germlines [46]. By contrast, high-throughput sequencing results indicate that tsRNAs exist in all the domains of life, with some tsRNA sequences nearly identical between humans and bacteria [27]. The conservation patterns of tsRNAs were more pronounced when we focused on two Drosophila species, D. melanogaster and D. virilis, which diverged more than 60 million years ago [47]. We previously found that $83.4 \%$ of the tsRNA species detected in $D$. virilis have the identical sequences detected in the small RNA sequencing libraries of D. melanogaster, and the abundance of the $5^{\prime}$ tsRNAs was significantly correlated in these two species [23]. Overall, these results suggest that tsRNAs have a very ancient origin, and the sequences and expression levels of tsRNA can be highly conserved. It will be interesting to investigate in the future whether the conserved tsRNAs have conserved target genes that are maintained due to functional constraints during evolution.

\section{4. tsRNA-Mediated AGO-Independent Translational Regulation}

Despite the growing knowledge of tsRNAs, the underlying molecular mechanisms of tsRNAmediated regulation are not yet well understood [5,19-22]. Numerous studies have demonstrated that tsRNAs play vital roles in translational regulation through an AGO-independent approach [48]. Specifically, tsRNAs might participate in translational control by interacting with the general translation machinery, or high-order cytoplasmic structures such as polyribosomes, processing bodies, and stress granules. These findings are briefly summarized as follows. 


\subsection{Terminal Oligoguanine (TOG) $5^{\prime}$ tRNA-Halves Displacing Translation Initiation Factors from $m R N A s$}

In mammalian cells, ANG is induced upon stress to generate tRNA-halves which subsequently induce the assembly of stress granules and suppress protein synthesis in an eIF2 $\alpha$-independent manner $[30,31,49,50]$. Remarkably, two tRNA-halves ( $5^{\prime}$-tsRNA ${ }^{\text {Ala }}$ and $5^{\prime}$-tsRNA ${ }^{\text {Cys }}$ ) whose $5^{\prime}$ ends have four to five guanine residues ("terminal oligoguanine", or TOG) have significant translation repressive effects [51]. It has been demonstrated that these TOG motifs can form intermolecular RNA G-quadruplexes which displace the translation initiation factor eIF4G/eIF4A from mRNAs and slow down translational initiation [51-54].

\section{2. tsRNAs Binding Multi-Synthetase Complex (MSC) to Effect Translation}

During protein biosynthesis in eukaryotes, multiple aminoacyl-tRNA synthetases and accessory factors constitute a multienzyme complex (multi-synthetase complex, or "MSC"), which plays a key role in translational elongation by delivering charged tRNAs to the ribosomes and recycling deacylated tRNAs [55-57]. A recent study suggests that human $5^{\prime}$ tsRNA ${ }^{\text {Gln }}$ interacts with the MSC, which is associated with global translation repression [58] (Figure 2A). Curiously, it was also discovered that overexpression of the $5^{\prime}$-tsRNA ${ }^{\text {Gln }}$ leads to increased translation of ribosomal and poly(A)-binding proteins due to an unknown reason [58].

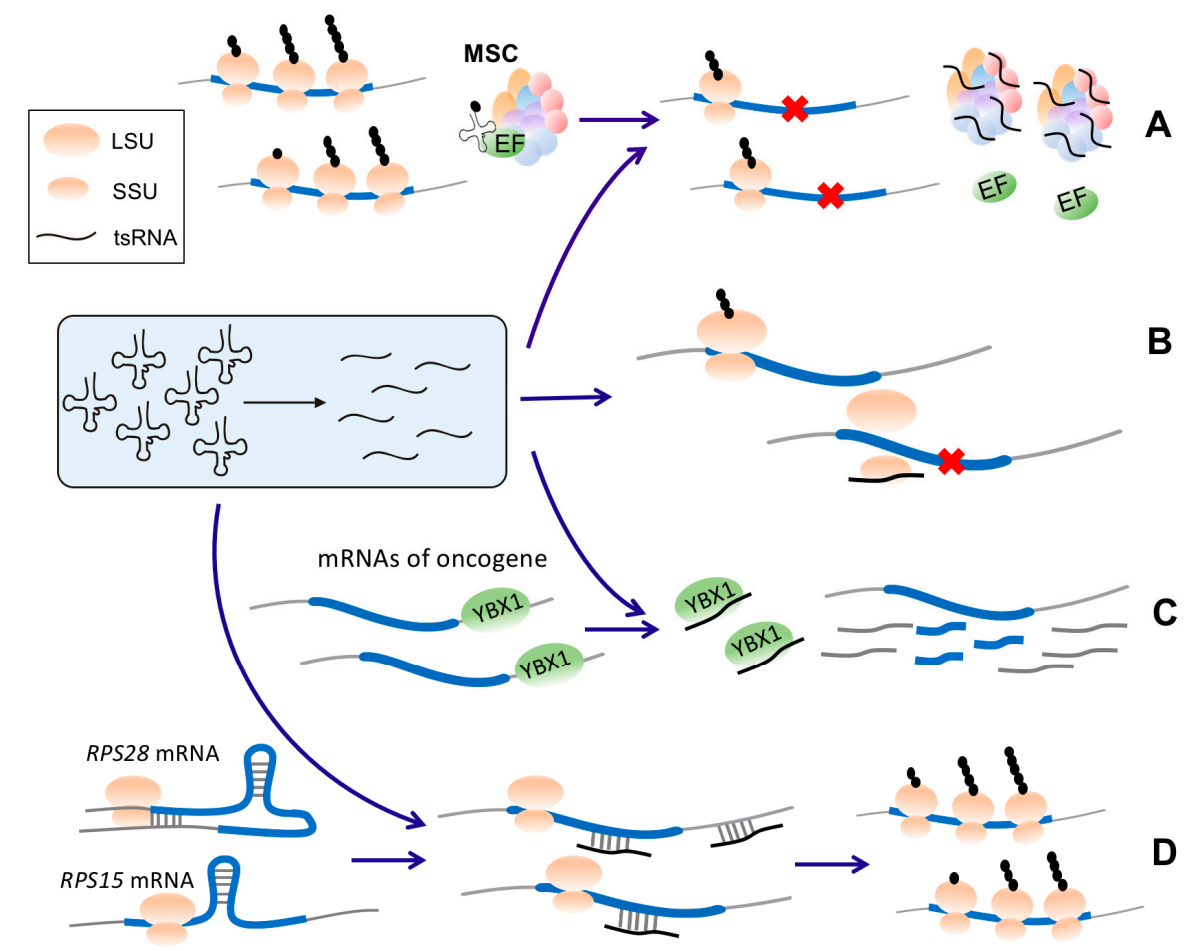

Figure 2. The Argonaute (AGO)-independent translation regulation modes mediated by tsRNAs. (A) In human cells, the multi-synthetase complex (MSC) can associate with elongation factors (EFs) to deliver charged tRNAs to the ribosomes. A $5^{\prime}$-tsRNA ${ }^{\text {Gln }}$ interferes with this process by interacting with MSC, which impedes protein translation. (B) In Haloferax volcanii, $5^{\prime}$-tsRNA ${ }^{\mathrm{Val}}$ can bind to small ribosomal subunits, which inhibits formation of the translation initiation complex and reduces protein translation under stress conditions. (C) Certain oncogenic mRNAs are stabilized if their $3^{\prime}$ UTRs are bound by YBX1. In breast cancer cells, several tsRNAs can competitively bind to YBX1, which destabilizes such oncogenic mRNAs by displacing them from YBX1. (D) A 22-nt $3^{\prime}$ tsRNA-LeuCAG binds the mRNAs of two ribosomal proteins (RPS28 and RPS15) to unfold their secondary structures and enhance their translation. For RPS28 mRNA, one target site of $3^{\prime}$ tsRNA-LeuCAG is located in the coding sequence (CDS) and the other target site is located in $3^{\prime} \mathrm{UTR}$; for RPS15 mRNA, the tsRNA target site is located in CDS. 


\section{3. tsRNAs Competing for Ribosomes}

It has been shown that in the halophilic archaeon Haloferax volcanii, a stress-induced tsRNA $\left(5^{\prime}\right.$-tsRNA $\left.{ }^{\mathrm{Val}}\right)$ can bind to the small ribosomal subunits, which interferes with the translation initiation complex formation of mRNAs and inhibits protein translation $[59,60]$ (Figure 2B).

\subsection{Competitive Binding of tsRNAs to YBX1 to Destabilize YBX1-Bound mRNAs}

YBX1 is an RNA-binding protein that stabilizes many oncogenic mRNAs by binding their $3^{\prime}$ UTRs. The binding motif recognized by YBX1 is an 8-mer sequence that is called CU-box [11]. The positions 2 and 3 of the CU-box motif are predominantly $C$ and $U$, respectively. YBX1 can also bind several tsRNAs (derived from tRNA ${ }^{\text {Glu }}$, tRNA $^{\text {Asp }}$, $\mathrm{tRNA}^{\mathrm{Gly}}$, and $\mathrm{tRNA}^{\mathrm{Tyr}}$ ) that have the CU-box. In breast cancer cells, those tsRNAs are induced and competitively bind to YBX1, which displaces the oncogenic mRNAs from YBX1. As a consequence, the oncogenic transcripts that are displaced from YBX1 by tsRNAs are destabilized, which further suppresses cancer progression [11] (Figure 2C).

\section{5. tsRNAs Unfolding Secondary Structure of Target mRNAs}

Although most tsRNA-mediated regulation is associated with reduced translational efficiency, it has been reported that a 22-nt $3^{\prime}$ tsRNA-Leu ${ }^{\mathrm{CAG}}$ binds the mRNAs of two ribosomal proteins (RPS28 and RPS15) to unfold their secondary structures and enhance their translation [14,54] (Figure 2D). Interesting, the binding between $3^{\prime}$ tsRNA-LeuCAG and the target mRNAs does not require AGO proteins [14]. Additionally, the inhibition of $3^{\prime}$ tsRNA-Leu ${ }^{C A G}$ impairs ribosome biogenesis by decreasing the number of $40 \mathrm{~S}$ ribosomal subunits [14]. Remarkably, the $3^{\prime}$ tsRNA-LeuCAG could induce apoptosis in rapidly dividing cells or in a patient-derived orthotopic hepatocellular carcinoma model in mice, highlighting its regulatory roles in cancer [14].

\section{Regulatory Functions of AGO-Bound tsRNAs}

Although many studies suggest tsRNA-mediated regulation can be exerted through an AGOindependent approach, others have demonstrated that tsRNAs are bound by AGO proteins in a wide range of species, including ciliates [61,62], plants [63], silkworms [64], flies [43], mice [65], the common marmoset [66], and humans [10,67] (Figure 3A). It was found that among human AGO1-4 proteins, tsRNAs are preferentially associated with AGO3 and 4 over AGO1 and 2 in HEK293 cells [68] (Figure 3A). Also, tsRNAs are associated with human Hiwi2, a PIWI paralog in the AGO family that is associated with the piRNA pathway and abundantly expressed in normal and tumor somas [65] (Figure 3A). Furthermore, many studies indicate that the complementarity between tsRNAs and target mRNAs is indispensable for efficient silencing $[10,27,32,63,68]$. For example, one 22 -nt $3^{\prime}$ tsRNA-Gly GCC (CU1276) was shown to associate with all four human AGO proteins and repress the target genes in a miRNA-like approach [10]. One $\sim 30$-nt $5^{\prime}$ tRNA-GluCTC also suppresses its target genes in Hep-2 cells in a miRNA-like manner, although the pairing is nucleated at the $3^{\prime}$ - instead of the $5^{\prime}$-portion of this tsRNA [32]. Remarkably, a re-analysis of the human CLASH (cross-linking, ligation and sequencing of hybrids) data [69] has identified various AGO1-tsRNA-mRNA chimeras (Figure 3B), which suggests that tsRNAs regulate targets via an RNAi-like manner [27]. Moreover, in Tetrahymena thermophile, the Piwi protein Twi12 binds $3^{\prime}$-tsRNAs to activate Xrn2 to induce the processing of cellular rRNAs [61] (Figure 3A). Altogether, these studies demonstrate that in many circumstances tsRNAs are bound with AGO proteins to exert the regulatory functions. 


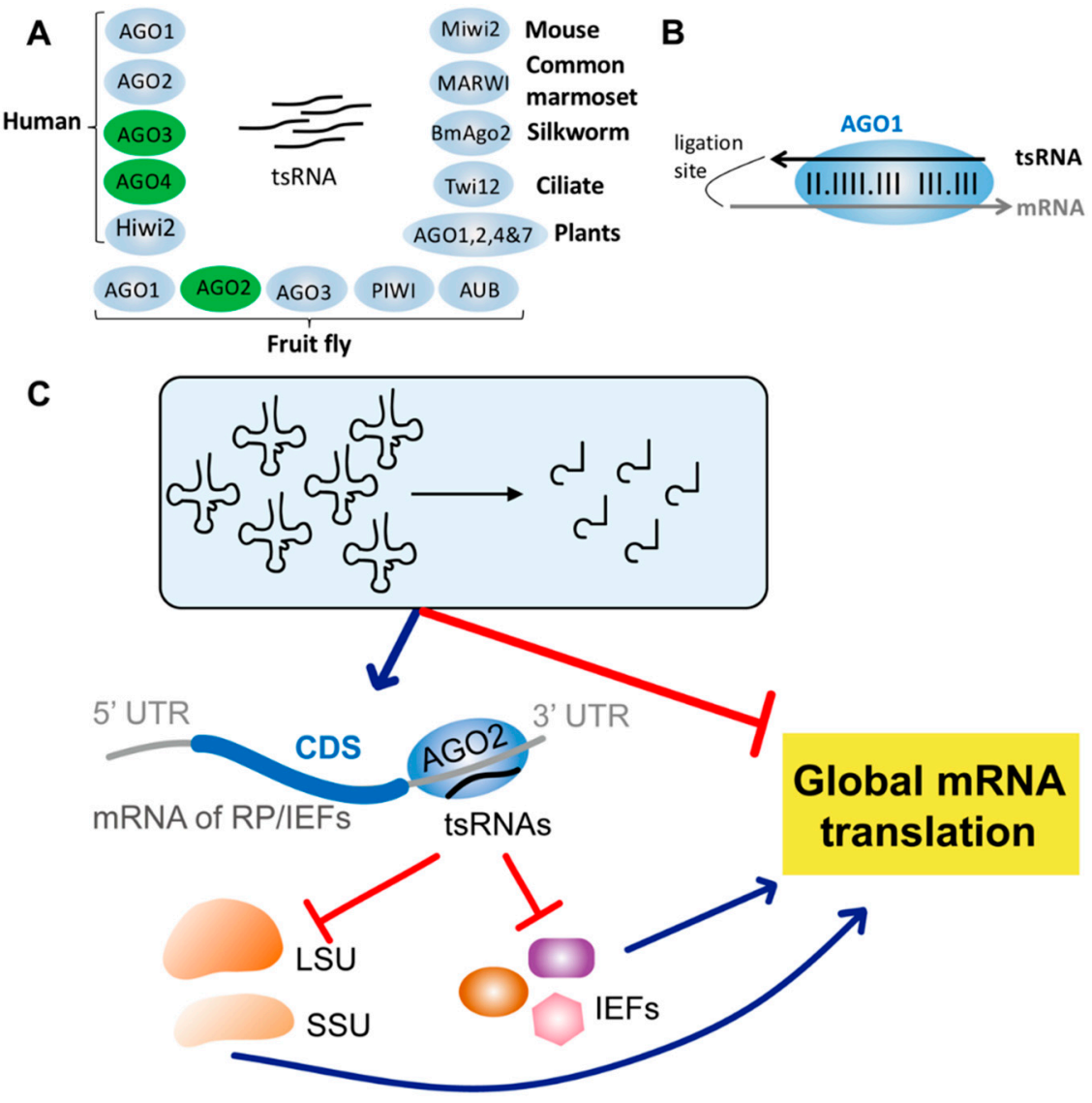

Figure 3. AGO-dependent tsRNA-mediated regulation. (A) tsRNAs are bound by AGO proteins in various species. In humans, tsRNAs are preferentially associated with AGO3 and 4 over AGO1 and 2 [68], and tsRNAs are also bound by Hiwi2 [65]. In Drosophila, tsRNAs are bound by AGO1, AGO2, AGO3, PIWI, and AUB. In S2 cells, tsRNAs are preferentially bound by AGO2 over AGO1 [23]. tsRNAs are also bound by Miwi2 in mice [65], by MARWI in the common marmoset [66], by BmAgo2 in silkworms [64], by Twi12 in ciliates [61,62], and by AGO1, 2, 4 and 7 in plants [63]. (B) The tsRNA-mRNA chimeras that are bound by AGO1 as revealed by human cross-linking, ligation and sequencing of hybrids (CLASH) data. (C) Drosophila tsRNAs suppress global translation by impeding ribosome biogenesis. Drosophila AGO2-bound tsRNAs preferentially inhibit translation of mRNAs of the ribosome proteins (RPs) or translational initiation or elongation factors (IEFs) through a RNAi-like approach, leading to attenuated global translation. Meanwhile, the processing of tRNA into tsRNAs also inhibits global translation since the abundance of tRNAs is reduced.

\section{Drosophila tsRNAs Inhibiting Global Translation by Impeding Ribosome Biogenesis}

Among the five AGO proteins in Drosophila, AGO1 and AGO2 primarily bind miRNAs and endogenous siRNAs, respectively; AGO3, PIWI, and AUB, which are mainly expressed in germline cells, primarily bind piRNAs [2,70] (Figure 3A). By analyzing the small RNAs that were associated with different AGO proteins (IP-Seq), we previously found that the short tsRNAs that have similar lengths as miRNAs or siRNAs (20-22 nt) are preferentially bound by AGO2 over AGO1 in Drosophila S2 cells, and the long tsRNAs that have similar lengths as piRNAs (24-29 nt) tend to be bound by AGO3, AUB and PIWI in the ovaries. These results suggest that tsRNAs might exert a regulatory function through an RNAi-like approach. To further probe the function of the tsRNAs, we selected 12 tsRNAs (most of them are bound by AGO2 in the IP-Seq data) and transfected each individual single-stranded tsRNA mimic into S2 cells. The polysome profiling analyses indicated the majority of tsRNAs had profound inhibitory effects on global mRNA translation. Interestingly, our mRNA-Seq and Ribo-Seq [71,72] experiments after cellular transfection of three tsRNAs suggest these tsRNAs 
recognize target mRNAs through conserved antisense matching and suppress translation rather than degrade mRNAs of the target genes [23].

The target prediction results suggested that AGO2-bound tsRNAs preferentially suppress translation of the key components of the general translation machinery such as ribosome proteins (RPs) and translational initiation or elongation factors (IEFs). We also found the expression profiles of the AGO2-bound tsRNAs reprogrammed under cellular stress to modulate translation of the RPs or IEFs. Moreover, we showed that tsRNA-mediated repression is dependent on AGO2 in Drosophila. First, we found the translational efficiencies of tsRNA targets are upregulated after AGO2 knock-down in S2 cells, and this pattern is especially strong for RPs or IEFs. Second, we found the targets of the upregulated tsRNAs are downregulated in translation during starvation. However, this pattern disappeared when we knocked down AGO2. Our results suggested Drosophila AGO2-bound tsRNAs inhibit global translation by preferentially suppressing translation of RPs or IEFs through an RNAi-like approach (Figure 3C). Our results also suggested that tsRNA-mediated regulation may be crucial for energy homeostasis and metabolic adaptation in cellular systems [23].

Why do tsRNAs preferentially target mRNAs of RPs or IEFs? We found Drosophila AGO2 preferentially bound "AAG" containing 7-mer motifs that are significantly enriched in the mRNAs of RPs or IEFs. Therefore, we speculate that the antisense pairing between tsRNAs and mRNAs of RPs or IEFs might be facilitated by the tethering effects of AGO2. It is possible that the preferential pairing between AGO2-bound tsRNAs and mRNAs of RPs or IEFs are due to long-term co-evolution between their sequences.

\section{Concluding Remarks and Future Perspectives: Taking Drosophila tsRNAs as an Example}

The tsRNA-mediated regulation adds another layer of regulatory complexity. Understanding the fundamental biology of tsRNAs remains the subject of intense interest and deserves further systematic studies. However, significant gaps remain in our understanding of the biogenesis, molecular mechanisms and evolutionary principles of tsRNA-mediated gene regulation. Specifically, taking tsRNAs in Drosophila as an example, the following issues remain to be addressed in the near future.

\subsection{The Biogenesis of Drosophila tsRNAs}

We previously found that in Drosophila, the short tsRNAs that have similar lengths as miRNAs or siRNAs (20-22 nt) are preferentially bound by AGO2 over AGO1 in Drosophila S2 cells, and the long tsRNAs that have similar lengths as piRNAs (24-29 nt) tend to be bound by AGO3, AUB and PIWI in the ovaries [23]. However, the genes and pathways crucial for tsRNA biogenesis in the soma and germlines are still poorly understood. Although ANG and Rny1 are involved in the biogenesis of tRNA-halves in vertebrates and yeasts respectively, ANG does not exist in Drosophila, and whether the ortholog of Rny1 in Drosophila participates in tsRNA biogenesis is still questionable. Moreover, whether the key players participating in the miRNAs or siRNAs biogenesis pathways such as Dcr-1 and $r 2 d 2$ influence tsRNA generation is not well understood at this moment $[23,27]$. Interestingly, it has been nicely demonstrated that the biogenesis of tsRNAs is dependent on key factors in the piRNA pathway such as Armi, Zuc, and dGasz in the Drosophila KC167 cell line [73]. Altogether, these studies suggest that the biogenesis of tsRNAs might be different in the soma and germlines of Drosophila, and future studies are required to better understand the detailed mechanisms underlying the biogenesis of tsRNAs.

\subsection{The Molecular Mechanism by which Drosophila tsRNAs Inhibit Translation of the Targets}

Our results suggest that the AGO2-bound tsRNAs recognize target mRNAs through conserved antisense matching and suppress translation rather than degrade mRNAs of the target genes in Drosophila [23]. However, the molecular mechanisms underlying the tsRNA-mediated translational suppression are not well understood at this moment. Functional genomics approaches such as CLEAR (covalent ligation of endogenous Argonaute-bound RNAs)-CLIP [74] might help identify the in vivo 
tsRNA-target chimera and help decipher the molecular mechanism by which Drosophila tsRNAs inhibit translation of the targets.

\subsection{The Function of piRNA-like tsRNAs in Drosophila Germlines}

Recent studies indicate that mammalian tsRNA are crucial for sperm maturation and fertilization in mammals [6,17], or the intergenerational inheritance of an acquired metabolic disorder [18,75]. In the ovaries of Drosophila, the tsRNAs are associated with AGO3, AUB, and PIWI and have similar length distributions (23-29 nt) as piRNAs [23]. We previously found the translational efficiency of the top target mRNAs of the AUB-bound tsRNAs is significantly lower than that of the non-targets in the mature oocytes but not in the activated eggs [23]. Hence, it is possible that the piRNA-like tsRNAs might play important roles in translational control during the development of the Drosophila germlines and early embryos. However, further studies are required for a better understanding of the detailed mechanisms in this process.

\subsection{The role of RNA Modifications on Biogenesis and Function of tRNAs.}

There are extensive post-transcriptional modifications in tRNAs [76-79]. Several studies have demonstrated how tRNA modifications might affect the biogenesis and functions of tsRNAs. A considerable number of TOG-containing tsRNAs in human embryonic stem cells (hESCs) are centered at $18 \mathrm{nt}$, and these endogenous $5^{\prime}$ tsRNAs are termed mini TOGs (mTOGs) [80]. The uridine residues at position 8 (U8) of the mTOGs that harbor a specific $\Psi$-consensus motif could be highly modified as $\Psi$ by the PUS7 $\Psi$ synthase in hESCs. It has been shown that that $\Psi$ could strongly promote the association between mTOGs and polyadenylate-binding protein 1 (PABPC1), which regulates mRNA translation by inhibiting PABPC1 recruitment to eIF4F and controls cell fate determination in stem cells [80]. Also, a previous study suggested the methylation of tRNA mediated by Dnmt2 (DNA methyltransferase 2) could inhibit stress-induced ribonuclease cleavage of tRNAs in Drosophila, which suggests that Dnmt2-mediated tRNA methylation plays a regulatory role in tsRNA biogenesis under stress [81]. NSUN2 is the cytosine-5 RNA methylase that methylates the vast majority of tRNAs. NSUN2-mediated tRNA methylation could protect tRNAs from ANG cleavage in mice and humans $[82,83]$. The loss of NSUN2-mediated cytosine-5 tRNA methylation could lead to elevated levels of tsRNAs that are generated by ANG cleavage, which further impairs mammalian brain development [82]. However, given the high diversity of tRNA modifications across different tissues, developmental stages and species, intense efforts are needed to decipher the relationship between tRNA modification and the biogenesis and function of tsRNAs in future studies.

Author Contributions: S.D., Y.W. and J.L. carried out the primary literature research; S.D. and Y.W. drafted the figures; J.L. wrote the manuscript.

Funding: Related research in the authors' laboratories is funded by grants from the Ministry of Science and Technology of the People's Republic of China (2016YFA0500800), the National Natural Science Foundation of China (No. 91731301, 31571333 and 91431101), and the Peking-Tsinghua Center for Life Science (J.L.).

Conflicts of Interest: The authors declare no conflicts of interest.

\section{References}

1. Jacquier, A. The complex eukaryotic transcriptome: Unexpected pervasive transcription and novel small RNAs. Nat. Rev. Genet. 2009, 10, 833-844. [CrossRef] [PubMed]

2. Ghildiyal, M.; Zamore, P.D. Small silencing RNAs: An expanding universe. Nat. Rev. Genet. 2009, 10, 94-108. [CrossRef] [PubMed]

3. Shigematsu, M.; Honda, S.; Kirino, Y. Transfer RNA as a source of small functional RNA. J. Mol. Biol. Mol. Imaging 2014, 1, 8. [PubMed]

4. Keam, S.P.; Hutvagner, G. tRNA-derived fragments (tRFs): Emerging new roles for an ancient RNA in the regulation of gene expression. Life 2015, 5, 1638-1651. [CrossRef] [PubMed] 
5. Kumar, P.; Kuscu, C.; Dutta, A. Biogenesis and function of transfer RNA-related fragments (tRFs). Trends Biochem. Sci. 2016, 41, 679-689. [CrossRef] [PubMed]

6. Peng, H.; Shi, J.; Zhang, Y.; Zhang, H.; Liao, S.; Li, W.; Lei, L.; Han, C.; Ning, L.; Cao, Y.; et al. A novel class of tRNA-derived small RNAs extremely enriched in mature mouse sperm. Cell Res. 2012, 22, 1609-1612. [CrossRef] [PubMed]

7. Li, S.; Xu, Z.; Sheng, J. tRNA-Derived Small RNA: A Novel Regulatory Small Non-Coding RNA. Genes 2018, 9, 246. [CrossRef] [PubMed]

8. Li, Y.; Luo, J.; Zhou, H.; Liao, J.Y.; Ma, L.M.; Chen, Y.Q.; Qu, L.H. Stress-induced tRNA-derived RNAs: A novel class of small RNAs in the primitive eukaryote Giardia lamblia. Nucleic Acids Res. 2008, 36, 6048-6055. [CrossRef] [PubMed]

9. Cole, C.; Sobala, A.; Lu, C.; Thatcher, S.R.; Bowman, A.; Brown, J.W.; Green, P.J.; Barton, G.J.; Hutvagner, G. Filtering of deep sequencing data reveals the existence of abundant Dicer-dependent small RNAs derived from tRNAs. RNA 2009, 15, 2147-2160. [CrossRef] [PubMed]

10. Maute, R.L.; Schneider, C.; Sumazin, P.; Holmes, A.; Califano, A.; Basso, K.; Dalla-Favera, R. tRNA-derived microRNA modulates proliferation and the DNA damage response and is down-regulated in $\mathrm{B}$ cell lymphoma. Proc. Natl. Acad. Sci. USA 2013, 110, 1404-1409. [CrossRef] [PubMed]

11. Goodarzi, H.; Liu, X.; Nguyen, H.C.; Zhang, S.; Fish, L.; Tavazoie, S.F. Endogenous tRNA-Derived Fragments Suppress Breast Cancer Progression via YBX1 Displacement. Cell 2015, 161, 790-802. [CrossRef] [PubMed]

12. Honda, S.; Loher, P.; Shigematsu, M.; Palazzo, J.P.; Suzuki, R.; Imoto, I.; Rigoutsos, I.; Kirino, Y. Sex hormone-dependent tRNA halves enhance cell proliferation in breast and prostate cancers. Proc. Natl. Acad. Sci. USA 2015, 112, E3816-E3825. [CrossRef] [PubMed]

13. Pekarsky, Y.; Balatti, V.; Palamarchuk, A.; Rizzotto, L.; Veneziano, D.; Nigita, G.; Rassenti, L.Z.; Pass, H.I.; Kipps, T.J.; Liu, C.G.; et al. Dysregulation of a family of short noncoding RNAs, tsRNAs, in human cancer. Proc. Natl. Acad. Sci. USA 2016, 113, 5071-5076. [CrossRef] [PubMed]

14. Kim, H.K.; Fuchs, G.; Wang, S.; Wei, W.; Zhang, Y.; Park, H.; Roy-Chaudhuri, B.; Li, P.; Xu, J.; Chu, K.; et al. A transfer-RNA-derived small RNA regulates ribosome biogenesis. Nature 2017, 552, 57-62. [CrossRef] [PubMed]

15. Martinez, G.; Choudury, S.G.; Slotkin, R.K. tRNA-derived small RNAs target transposable element transcripts. Nucleic Acids Res. 2017, 45, 5142-5152. [CrossRef] [PubMed]

16. Schorn, A.J.; Gutbrod, M.J.; LeBlanc, C.; Martienssen, R. LTR-retrotransposon control by tRNA-derived small RNAs. Cell 2017, 170, 61-71.e11. [CrossRef] [PubMed]

17. Sharma, U.; Conine, C.C.; Shea, J.M.; Boskovic, A.; Derr, A.G.; Bing, X.Y.; Belleannee, C.; Kucukural, A.; Serra, R.W.; Sun, F; et al. Biogenesis and function of tRNA fragments during sperm maturation and fertilization in mammals. Science 2016, 351, 391-396. [CrossRef] [PubMed]

18. Chen, Q.; Yan, M.; Cao, Z.; Li, X.; Zhang, Y.; Shi, J.; Feng, G.H.; Peng, H.; Zhang, X.; Zhang, Y.; et al. Sperm tsRNAs contribute to intergenerational inheritance of an acquired metabolic disorder. Science 2016, 351, 397-400. [CrossRef] [PubMed]

19. Anderson, P.; Ivanov, P. tRNA fragments in human health and disease. FEBS Lett. 2014, 588, 4297-4304. [CrossRef] [PubMed]

20. Pederson, T. Regulatory RNAs derived from transfer RNA? RNA 2010, 16, 1865-1869. [CrossRef] [PubMed]

21. Raina, M.; Ibba, M. tRNAs as regulators of biological processes. Front. Genet. 2014, 5, 171. [CrossRef] [PubMed]

22. Sobala, A.; Hutvagner, G. Transfer RNA-derived fragments: Origins, processing, and functions. Wiley Interdiscip. Rev.-RNA 2011, 2, 853-862. [CrossRef] [PubMed]

23. Luo, S.; He, F.; Luo, J.; Dou, S.; Wang, Y.; Guo, A.; Lu, J. Drosophila tsRNAs preferentially suppress general translation machinery via antisense pairing and participate in cellular starvation response. Nucleic Acids Res. 2018, 46, 5250-5268. [CrossRef] [PubMed]

24. Kirchner, S.; Ignatova, Z. Emerging roles of tRNA in adaptive translation, signalling dynamics and disease. Nat. Rev. Genet. 2014, 16, 98. [CrossRef] [PubMed]

25. Shen, Y.; Yu, X.; Zhu, L.; Li, T.; Yan, Z.; Guo, J. Transfer RNA-derived fragments and tRNA halves: Biogenesis, biological functions and their roles in diseases. J. Mol. Med. 2018, 96, 1167-1176. [CrossRef] [PubMed]

26. Gebetsberger, J.; Polacek, N. Slicing tRNAs to boost functional ncRNA diversity. RNA Biol. 2013, 10, 1798-1806. [CrossRef] [PubMed] 
27. Kumar, P.; Anaya, J.; Mudunuri, S.B.; Dutta, A. Meta-analysis of tRNA derived RNA fragments reveals that they are evolutionarily conserved and associate with AGO proteins to recognize specific RNA targets. BMC Biol. 2014, 12, 78. [CrossRef] [PubMed]

28. Kumar, P.; Mudunuri, S.B.; Anaya, J.; Dutta, A. tRFdb: A database for transfer RNA fragments. Nucleic Acids Res. 2015, 43, D141-D145. [CrossRef] [PubMed]

29. Thompson, D.M.; Lu, C.; Green, P.J.; Parker, R. tRNA cleavage is a conserved response to oxidative stress in eukaryotes. RNA 2008, 14, 2095-2103. [CrossRef] [PubMed]

30. Emara, M.M.; Ivanov, P.; Hickman, T.; Dawra, N.; Tisdale, S.; Kedersha, N.; Hu, G.F.; Anderson, P. Angiogenin-induced tRNA-derived stress-induced RNAs promote stress-induced stress granule assembly. J. Biol. Chem. 2010, 285, 10959-10968. [CrossRef] [PubMed]

31. Yamasaki, S.; Ivanov, P.; Hu, G.F.; Anderson, P. Angiogenin cleaves tRNA and promotes stress-induced translational repression. J. Cell Biol. 2009, 185, 35-42. [CrossRef] [PubMed]

32. Wang, Q.; Lee, I.; Ren, J.; Ajay, S.S.; Lee, Y.S.; Bao, X. Identification and functional characterization of tRNA-derived RNA fragments (tRFs) in respiratory syncytial virus infection. Mol. Ther. J. Am. Soc. Gene Ther. 2013, 21, 368-379. [CrossRef] [PubMed]

33. Saikia, M.; Hatzoglou, M. The Many Virtues of tRNA-derived Stress-induced RNAs (tiRNAs): Discovering Novel Mechanisms of Stress Response and Effect on Human Health. J. Biol. Chem. 2015, 290, 29761-29768. [CrossRef] [PubMed]

34. Fu, H.; Feng, J.; Liu, Q.; Sun, F.; Tie, Y.; Zhu, J.; Xing, R.; Sun, Z.; Zheng, X. Stress induces tRNA cleavage by angiogenin in mammalian cells. FEBS Lett. 2009, 583, 437-442. [CrossRef] [PubMed]

35. Thompson, D.M.; Parker, R. The RNase Rny1p cleaves tRNAs and promotes cell death during oxidative stress in Saccharomyces cerevisiae. J. Cell Biol. 2009, 185, 43-50. [CrossRef] [PubMed]

36. Ambrosio, L.; Morriss, S.; Riaz, A.; Bailey, R.; Ding, J.; MacIntosh, G.C. Phylogenetic analyses and characterization of RNase X25 from Drosophila melanogaster suggest a conserved housekeeping role and additional functions for RNase T2 enzymes in protostomes. PLoS ONE 2014, 9, e105444. [CrossRef] [PubMed]

37. Lyons, S.M.; Fay, M.M.; Akiyama, Y.; Anderson, P.J.; Ivanov, P. RNA biology of angiogenin: Current state and perspectives. RNA Biol. 2017, 14, 171-178. [CrossRef] [PubMed]

38. Li, Z.; Ender, C.; Meister, G.; Moore, P.S.; Chang, Y.; John, B. Extensive terminal and asymmetric processing of small RNAs from rRNAs, snoRNAs, snRNAs, and tRNAs. Nucleic Acids Res. 2012, 40, 6787-6799. [CrossRef] [PubMed]

39. Babiarz, J.E.; Ruby, J.G.; Wang, Y.; Bartel, D.P.; Blelloch, R. Mouse ES cells express endogenous shRNAs, siRNAs, and other Microprocessor-independent, Dicer-dependent small RNAs. Genes Dev. 2008, 22, 2773-2785. [CrossRef] [PubMed]

40. Kuscu, C.; Kumar, P.; Kiran, M.; Su, Z.; Malik, A.; Dutta, A. tRNA fragments (tRFs) guide Ago to regulate gene expression post-transcriptionally in a Dicer-independent manner. RNA 2018, 24, 1093-1105. [CrossRef] [PubMed]

41. Torres, A.G.; Pineyro, D.; Rodriguez-Escriba, M.; Camacho, N.; Reina, O.; Saint-Leger, A.; Filonava, L.; Batlle, E.; de Pouplana, L.R. Inosine modifications in human tRNAs are incorporated the precursor tRNA level. Nucleic Acids Res. 2015, 43, 5145-5157. [CrossRef] [PubMed]

42. Zheng, G.; Qin, Y.; Clark, W.C.; Dai, Q.; Yi, C.; He, C.; Lambowitz, A.M.; Pan, T. Efficient and quantitative high-throughput tRNA sequencing. Nat. Methods 2015, 12, 835-837. [CrossRef] [PubMed]

43. Karaiskos, S.; Naqvi, A.S.; Swanson, K.E.; Grigoriev, A. Age-driven modulation of tRNA-derived fragments in Drosophila and their potential targets. Biol. Direct 2015, 10, 51. [CrossRef] [PubMed]

44. Liao, J.Y.; Guo, Y.H.; Zheng, L.L.; Li, Y.; Xu, W.L.; Zhang, Y.C.; Zhou, H.; Lun, Z.R.; Ayala, F.J.; Qu, L.H. Both endo-siRNAs and tRNA-derived small RNAs are involved in the differentiation of primitive eukaryote Giardia lamblia. Proc. Natl. Acad. Sci. USA 2014, 111, 14159-14164. [CrossRef] [PubMed]

45. Hsieh, L.C.; Lin, S.I.; Shih, A.C.; Chen, J.W.; Lin, W.Y.; Tseng, C.Y.; Li, W.H.; Chiou, T.J. Uncovering small RNA-mediated responses to phosphate deficiency in Arabidopsis by deep sequencing. Plant Physiol. 2009, 151, 2120-2132. [CrossRef] [PubMed]

46. Shabalina, S.A.; Koonin, E.V. Origins and evolution of eukaryotic RNA interference. Trends Ecol. Evol. 2008, $23,578-587$. 
47. Tamura, K.; Subramanian, S.; Kumar, S. Temporal patterns of fruit fly (Drosophila) evolution revealed by mutation clocks. Mol. Biol. Evol. 2004, 21, 36-44. [CrossRef] [PubMed]

48. Sobala, A.; Hutvagner, G. Small RNAs derived from the 5 end of tRNA can inhibit protein translation in human cells. RNA Biol. 2013, 10, 553-563. [CrossRef] [PubMed]

49. Anderson, P.; Kedersha, N. Stress granules. Curr. Biol. 2009, 19, R397-R398. [CrossRef] [PubMed]

50. Thompson, D.M.; Parker, R. Stressing out over tRNA cleavage. Cell 2009, 138, 215-219. [CrossRef] [PubMed]

51. Ivanov, P.; Emara, M.M.; Villen, J.; Gygi, S.P.; Anderson, P. Angiogenin-induced tRNA fragments inhibit translation initiation. Mol. Cell 2011, 43, 613-623. [CrossRef] [PubMed]

52. Ivanov, P.; O’Day, E.; Emara, M.M.; Wagner, G.; Lieberman, J.; Anderson, P. G-quadruplex structures contribute to the neuroprotective effects of angiogenin-induced tRNA fragments. Proc. Natl. Acad. Sci. USA 2014, 111, 18201-18206. [CrossRef] [PubMed]

53. Lyons, S.M.; Gudanis, D.; Coyne, S.M.; Gdaniec, Z.; Ivanov, P. Identification of functional tetramolecular RNA G-quadruplexes derived from transfer RNAs. Nat. Commun. 2017, 8, 1127. [CrossRef] [PubMed]

54. Shi, J.; Zhang, Y.; Zhou, T.; Chen, Q. tsRNAs: The Swiss Army Knife for Translational Regulation. Trends Biochem. Sci. 2018. [CrossRef] [PubMed]

55. Mirande, M. Processivity of translation in the eukaryote cell: Role of aminoacyl-tRNA synthetases. FEBS Lett. 2010, 584, 443-447. [CrossRef] [PubMed]

56. David, A.; Netzer, N.; Strader, M.B.; Das, S.R.; Chen, C.Y.; Gibbs, J.; Pierre, P.; Bennink, J.R.; Yewdell, J.W. RNA binding targets aminoacyl-tRNA synthetases to translating ribosomes. J. Biol. Chem. 2011, 286, 20688-20700. [CrossRef] [PubMed]

57. Quevillon, S.; Robinson, J.C.; Berthonneau, E.; Siatecka, M.; Mirande, M. Macromolecular assemblage of aminoacyl-tRNA synthetases: Identification of protein-protein interactions and characterization of a core protein. J. Mol. Biol. 1999, 285, 183-195. [CrossRef] [PubMed]

58. Keam, S.P.; Sobala, A.; Ten Have, S.; Hutvagner, G. tRNA-derived RNA fragments associate with human multisynthetase complex (MSC) and modulate ribosomal protein translation. J. Proteome Res. 2017, 16, 413-420. [CrossRef] [PubMed]

59. Gebetsberger, J.; Wyss, L.; Mleczko, A.M.; Reuther, J.; Polacek, N. A tRNA-derived fragment competes with mRNA for ribosome binding and regulates translation during stress. RNA Biol. 2017, 14, 1364-1373. [CrossRef] [PubMed]

60. Gebetsberger, J.; Zywicki, M.; Kunzi, A.; Polacek, N. tRNA-derived fragments target the ribosome and function as regulatory non-coding RNA in Haloferax volcanii. Archaea 2012, 2012, 260909. [CrossRef] [PubMed]

61. Couvillion, M.T.; Bounova, G.; Purdom, E.; Speed, T.P.; Collins, K. A Tetrahymena Piwi bound to mature tRNA $3^{\prime}$ fragments activates the exonuclease Xrn2 for RNA processing in the nucleus. Mol. Cell 2012, 48, 509-520. [CrossRef] [PubMed]

62. Couvillion, M.T.; Sachidanandam, R.; Collins, K. A growth-essential Tetrahymena Piwi protein carries tRNA fragment cargo. Genes Dev. 2010, 24, 2742-2747.

63. Loss-Morais, G.; Waterhouse, P.M.; Margis, R. Description of plant tRNA-derived RNA fragments (tRFs) associated with argonaute and identification of their putative targets. Biol. Direct 2013, 8, 6. [CrossRef] [PubMed]

64. Nie, Z.; Zhou, F.; Li, D.; Lv, Z.; Chen, J.; Liu, Y.; Shu, J.; Sheng, Q.; Yu, W.; Zhang, W.; et al. RIP-seq of BmAgo2-associated small RNAs reveal various types of small non-coding RNAs in the silkworm, Bombyx mori. BMC Genom. 2013, 14, 661. [CrossRef] [PubMed]

65. Keam, S.P.; Young, P.E.; McCorkindale, A.L.; Dang, T.H.; Clancy, J.L.; Humphreys, D.T.; Preiss, T.; Hutvagner, G.; Martin, D.I.; Cropley, J.E.; et al. The human Piwi protein Hiwi2 associates with tRNA-derived piRNAs in somatic cells. Nucleic Acids Res. 2014, 42, 8984-8995. [CrossRef] [PubMed]

66. Hirano, T.; Iwasaki, Y.W.; Lin, Z.Y.; Imamura, M.; Seki, N.M.; Sasaki, E.; Saito, K.; Okano, H.; Siomi, M.C.; Siomi, H. Small RNA profiling and characterization of piRNA clusters in the adult testes of the common marmoset, a model primate. RNA 2014, 20, 1223-1237. [CrossRef] [PubMed]

67. Yeung, M.L.; Bennasser, Y.; Watashi, K.; Le, S.-Y.; Houzet, L.; Jeang, K.-T. Pyrosequencing of small non-coding RNAs in HIV-1 infected cells: Evidence for the processing of a viral-cellular double-stranded RNA hybrid. Nucleic Acids Res. 2009, 37, 6575-6586. [CrossRef] [PubMed] 
68. Haussecker, D.; Huang, Y.; Lau, A.; Parameswaran, P.; Fire, A.Z.; Kay, M.A. Human tRNA-derived small RNAs in the global regulation of RNA silencing. RNA 2010, 16, 673-695. [CrossRef] [PubMed]

69. Helwak, A.; Kudla, G.; Dudnakova, T.; Tollervey, D. Mapping the Human miRNA Interactome by CLASH Reveals Frequent Noncanonical Binding. Cell 2013, 153, 654-665. [CrossRef] [PubMed]

70. Carthew, R.W.; Sontheimer, E.J. Origins and mechanisms of miRNAs and siRNAs. Cell 2009, 136, 642-655. [CrossRef] [PubMed]

71. Ingolia, N.T.; Ghaemmaghami, S.; Newman, J.R.; Weissman, J.S. Genome-wide analysis in vivo of translation with nucleotide resolution using ribosome profiling. Science 2009, 324, 218-223. [CrossRef] [PubMed]

72. Ingolia, N.T.; Lareau, L.F.; Weissman, J.S. Ribosome profiling of mouse embryonic stem cells reveals the complexity and dynamics of mammalian proteomes. Cell 2011, 147, 789-802. [CrossRef] [PubMed]

73. Vrettos, N.; Maragkakis, M.; Alexiou, P.; Mourelatos, Z. Kc167, a widely used Drosophila cell line, contains an active primary piRNA pathway. RNA 2017, 23, 108-118. [CrossRef] [PubMed]

74. Moore, M.J.; Scheel, T.K.H.; Luna, J.M.; Park, C.Y.; Fak, J.J.; Nishiuchi, E.; Rice, C.M.; Darnell, R.B. miRNA-target chimeras reveal miRNA 3 '-end pairing as a major determinant of Argonaute target specificity. Nat. Commun. 2015, 6, 8864. [CrossRef] [PubMed]

75. Chen, Q.; Yan, W.; Duan, E. Epigenetic inheritance of acquired traits through sperm RNAs and sperm RNA modifications. Nat. Rev. Genet. 2016, 17, 733. [CrossRef] [PubMed]

76. Phizicky, E.M.; Alfonzo, J.D. Do all modifications benefit all tRNAs? FEBS Lett. 2010, 584, 265-271. [CrossRef] [PubMed]

77. Han, L.; Phizicky, E.M. A rationale for tRNA modification circuits in the anticodon loop. RNA 2018, 24, 1277-1284. [CrossRef] [PubMed]

78. Lorenz, C.; Lünse, C.E.; Mörl, M. tRNA Modifications: Impact on Structure and Thermal Adaptation. Biomolecules 2017, 7, 35. [CrossRef] [PubMed]

79. Zhang, X.; Cozen, A.E.; Liu, Y.; Chen, Q.; Lowe, T.M. Small RNA Modifications: Integral to Function and Disease. Trends Mol. Med. 2016, 22, 1025-1034. [CrossRef] [PubMed]

80. Guzzi, N.; Ciesla, M.; Ngoc, P.C.T.; Lang, S.; Arora, S.; Dimitriou, M.; Pimkova, K.; Sommarin, M.N.E.; Munita, R.; Lubas, M.; et al. Pseudouridylation of tRNA-Derived Fragments Steers Translational Control in Stem Cells. Cell 2018, 173, 1204-1216 e1226. [CrossRef] [PubMed]

81. Schaefer, M.; Pollex, T.; Hanna, K.; Tuorto, F.; Meusburger, M.; Helm, M.; Lyko, F. RNA methylation by Dnmt2 protects transfer RNAs against stress-induced cleavage. Genes Dev. 2010, 24, 1590-1595. [CrossRef] [PubMed]

82. Blanco, S.; Dietmann, S.; Flores, J.V.; Hussain, S.; Kutter, C.; Humphreys, P.; Lukk, M.; Lombard, P.; Treps, L.; Popis, M.; et al. Aberrant methylation of tRNAs links cellular stress to neuro-developmental disorders. EMBO J. 2014, 33, 2020-2039. [CrossRef] [PubMed]

83. Frye, M.; Blanco, S. Post-transcriptional modifications in development and stem cells. Development 2016, 143, 3871-3881. [CrossRef] [PubMed]

(C) 2019 by the authors. Licensee MDPI, Basel, Switzerland. This article is an open access article distributed under the terms and conditions of the Creative Commons Attribution (CC BY) license (http:/ / creativecommons.org/licenses/by/4.0/). 